\title{
Numeric Country Code
}

National Cancer Institute

\section{Source}

National Cancer Institute. Numeric Country Code. NCI Thesaurus. Code C54640.

The numeric, three-digit country codes specified by the ISO 3166-1 country code standard. 